Session 1360

\title{
QUALITY ASSURANCE IN ENGINEERING EDUCATION THROUGH ISO 9001 - AN EXPERIENCE
}

\author{
Megat Johari Megat Mohd Noor, Mohd Rasid Osman, \\ Nor Kamariah Noordin, Rahman Wagiran, Desa Ahmad, Mohd Saleh Jaafar, \\ Zainuddin Mohd Yusof, Radin Umar Radin Sohadi
}

Universiti Putra Malaysia

\section{Introduction}

This paper presents the experiences of the School of Engineering, Universiti Putra Malaysia (UPM) in providing quality assurance to its engineering degree programmes through the newly embarked activity of implementing ISO 9001. Problems and solutions related to the certification of ISO 9001 from the conception stage until achieving the certification are highlighted. The implementation of the ISO 9001 quality system is to complement the existing quality assurance activities such as the accreditation by the Board of Engineers, Malaysia and the external examination and assessment processes.

Prior to the ISO 9001 certification exercise by the School of Engineering, there was an ambitious move by UPM to certify all activities covering the scope of teaching, research, consultancy and administration at the university level. Learning from the failure, which was mainly due to the lack of management commitment at nearly all levels that did not translate or permeate down the importance of the exercise, has led UPM to take a more cautious approach, i.e. to look at a small and manageable school and progressing there on.

The School of Veterinary Science was fortunate to be the first to be selected, and attained certification in late 1999. The documented procedures that were developed during the unsuccessful certification exercise became the source of reference for the School when developing their procedures. The School of Engineering, being one of the largest faculties was earmarked to follow upon successful certification at the School of Veterinary Science. However, the School being the forerunner at the university on ISO 9001, had decided to embark earlier than the approval given by the university.

A blueprint for obtaining certification was prepared in 1999 with a multi-prong approach; a trial-run of ISO9001, development and refinement of documented procedures and quality manual, strengthening of management commitment through workshops and meetings, training of staff on ISO 9001 and the documented procedures, team building activities, and establishing a core group to see the ISO 9001 programme through. 
Although the ultimate aim was to cover all the activities, the School later decided to limit the scope to teaching of undergraduates and supporting activities. These activities nevertheless involved all faculty and non-academic staff at the School of Engineering. The act of standardising teaching was initially seen as suppressing academic freedom that faculty has enjoyed all these years. Documentation and proof of records were considered moving backwards from the paperless management system. Despite some setbacks the multi-prong approach was able to instill an improved quality culture amongst the staff, both academic and clerical staff, changing skeptics to ardent supporters of the system.

\section{ISO 9001 - A Brief Excerpts}

ISO (International Organization for Standardization) first published its quality standards in 1987, revised them in 1994, and then republished an updated the version in 2000. In these newer version there are some changes being made to facilitate all the companies trying to achieve certification. Changes include new requirements, new flexibility, new emphasis, new structure and new approach ${ }^{[1]}$.

Historically the ISO 9000 standards were created from a chain of earlier military and governmental quality standards for example US military (Mil-Q-9858A) and NATO (AQAP1). In 1979, the British Standards Institution issued "BS 5750", which along with other existing standards such as Canada "Z-299" quality standards became the eventual basis for the present ISO9000 international standards. After ISO 9000 was issued, the British Standards Institution revised "BS 5750" to conform to the new composite standard ${ }^{[2]}$.

ISO 9000 is fairly simple to understand. Most of the difficulties with ISO 9000 lie in its implementation efforts and the subsequent translation from a generic set of quality guidelines to the specifics of a given company's operations ${ }^{[3]}$. In essence ISO 9000 can be summarized as ${ }^{[4]}$ :

1. SAY WHAT YOU DO - establish appropriate quality controls and systems

2. DO WHAT YOU SAY - ensure that everyone involved follows the established processes

3. SHOW ME - demonstrate compliance of your quality system to an external auditor

A study by Rao et. al. ${ }^{[5]}$ on the relationship between ISO 9000 and the level of quality management practices and quality results found out that ISO 9000 registered companies exhibited higher levels of quality leadership, information and analysis, strategic quality planning, human resource development, quality assurance, supplier relationships , customer orientation and quality results. Another by Calingo et. al. ${ }^{[6]}$ found that companies with ISO certification had obtained the following benefits:

1. Improved quality system

2. Comply with clients requirements

3. Gain competitive edge

4. Attain Total Quality Management

5. Gain additional export market

6. Quality documentation

7. Reduce quality problems

8. Encourage teamwork 


\section{The Early Years}

UPM was the first university in Malaysia to embark on implementing a full quality management system on all her activities, under the former Vice Chancellor, Professor Syed Jalaluddin. Representatives from various faculties were sent for a one-week training on the ISO 9001, to then became the core group in ensuring that the system was in place. The two representatives from the School of Engineering are currently appointed as the Dean of the School and the Head of the Quality Assurance Unit. Thus the spirit of the early years is not forgotten and seems to be reinforced with time.

The two representatives thereby conducted a workshop to disseminate the knowledge of ISO 9001 and formulated the documented procedures in the four scopes; teaching, research, consultancy services and administration at the School of Engineering. This was followed by another workshop to refine the documented procedures. These exercises gave birth to a core group of committed academics, the pioneers that pursued the establishment of a quality management system at the School. The documented procedures were later adapted and translated into the national language by the University to be used in her quest for establishing the university quality management system.

Although it was unfortunate that the first certification exercise at the university level was a failure, the compliance audit report was favourable in areas where the School was audited. A steering committee comprising committed academics from the School core group of the earlier unsuccessful certification exercise was formed to guide the School. A cautious approach was also taken where the scope only included teaching at the undergraduate level and the supporting activities that would satisfy the ISO 9001 requirements. The other activities would be included upon attaining certification. This approach was taken after learning from the University's failure in tackling the issue on a wider scale.

Teaching and its associated activities were seen to include all the staff, both academic and support staffs, at the School. Thus no one was spared from being involved in the quality management system. This was an important approach as everyone had to participate to ensure a successful implementation of the system. The School could have just opted for the scope of services, and it would have been easier to handle as the personnel involved were far smaller in number. The spirit then was to get everybody on board from the start.

\section{The Approach}

A steering committee was responsible in charting out the programme for the School to achieve certification in the scope mentioned earlier. Getting the management team highly motivated to implement the quality system was the first move. It also included committing financial resource to conduct ISO 9001 related activities. This was followed by a trial implementation phase upon completing the documentation process. The Adequacy and Compliance Audits phases followed the trial implementation phase. A series of training workshops to provide the understanding on the ISO 9001 and the documented procedures for staff was also included in the programme. Training workshops were also designed to provide motivation to staff to embrace the system willingly.

The documented procedures were prepared by a dedicated core group of academics and in the process of documenting the procedures the staff responsible for the activities or jobs were referred to. A series of workshops were held to improve and refine the procedures. Among 
the improvements made were the inclusion of deadlines in the activities and the need to keep records as proofs that the activities had been implemented. Activities that were not included or conducted minimally prior to the documentation exercise, such as, management review, corrective and preventive actions, internal quality audit, control of documents and statistical analysis were thus formulated. The documenting process was not a difficult activity as most of the time the procedures were already in place and the team was experienced in the documentation work.

After having completed the set of documented procedures, an external consultant was appointed to review the procedures to ensure that the requirements of the ISO 9001 were satisfied. A total of 48 procedures were developed and approved by the School of which 29 procedures were for the teaching scope while the remainder for the supporting activities. These procedures were also supported by several guidelines. Forms, checklists, log books, references and control lists were also produced to supplement the running of the system.

It was a cumbersome exercise and had created 'fear' in the staff, thinking that the School was imposing a new culture altogether. In fact it was just a documenting exercise on how the existing activities were conducted with minimum introduction of control measures to ensure an efficient implementation. The 'fear' was, however, justified as the staff was not fully aware of the requirement of the ISO 9001 standards.

The trial run as it was known prior to the Adequacy Audit was to get the staff to be familiarised with the documented procedures. It was implemented on the15th of May 2000 and numerous potential non-compliances were identified. It was concluded that many of the staff took the exercise for granted, as it was only a trial session. However, the trial phase acted as an eye-opener and set the scene for many that the School was really serious about implementing the system. The trial run was also helpful in providing information for refining the documented procedures further.

As the deadline for the Adequacy Audit was nearing, the core group was heavily engaged in reviewing the documented procedures to ensure ISO 9001 requirements were satisfied. The work extended into the weekends; despite an early start with the trial run. However, with the 'esprit de corps' shown by the core group, the painstaking activity of ensuring the completeness in the documented procedures was considerably enjoyable. The togetherness in developing and perfecting the documented procedures until the wee hour of the morning had created a bond within the core group that had also extended into other areas of involvement apart from managing the quality system.

The one-day Adequacy Audit by SIRIM (a government body, in charged of Standards), which was held on the $1^{\text {st }}$ of November 2000 , ran smoothly with three observations made to improve the documentation on the quality system. Even though it was only an Adequacy Audit, the participation and involvement by the staff to ensure a presentable working environment was enormous. Laboratories that were previously not well attended to were given a 'spring cleaning' and careful attention. The School building complex and its surrounding were given a new face-lift. More attentions were thus given to the working environment. The success at the Adequacy Audit was a milestone for the School as it had also converted many skeptics into supporters of the quality system.

The path towards the Compliance Audit was thus made much easier with the successful Adequacy Audit, although the subsequent effort to ensure a full compliance of the quality 
system was a tremendous task. A thorough programme of three internal audits was planned and implemented where in the first two audits the approach was to detect non-compliances by areas i.e., departments and divisions against documented procedures. In the final audit the approach was by documented procedures i.e., documented procedures against departments and divisions.

The School also adopted a system where each department or division has an Area Coordinator and a deputy appointed by the Dean upon recommendation by the respective heads. The Area Coordinator and the deputy were to provide assistance to the respective heads in ensuring compliance. The Area Coordinator had to be conversant with the documented procedures and act as a reference point for any enquiries from within.

The idea of having Area Coordinators monitoring the situation of compliance was to reduce the workload of the heads. However, it was noted that some of the heads delegated the work completely to the Area Coordinator without monitoring the progress of the work. The Area Coordinator had no authority to interfere with non-compliances and as such when dealing with difficult staff no follow up actions were carried out. Regular management meetings were thus conducted to overcome these difficulties where the heads had to report on the progress and the corrective and preventive actions to be implemented.

Although the Area Coordinators were independent in their audit, there were possibilities that the system might have been abused. As such the internal auditors appointed to audit the respective departments or division were from different departments or divisions that was being audited. The internal auditors did not refer to the audit records of the Area Coordinators in order to avoid biasness in their audit. A $100 \%$ audit was carried out in both the two earlier internal audits. No stones were left unturned in the process. The process was rather labourious but full knowledge of the compliance status were obtained.

The use of staff from outside the School as internal auditors during the second internal audit had some advantages such that the School of Engineering staff had to treat the exercise in a more serious manner. However, there was a tendency by these internal auditors to impose their views during the auditing process, which could have derailed what had been an accepted and appropriate practice. Following the second internal audit, the use of external staff as internal auditors was abandoned so as to minimise the interference. There is no end to perfecting the procedures but rapid changes to the procedures would cause the staff to be disorientated or confused.

The approach to final internal audit where respective documented procedures were audited against departments and divisions made sure that a standardised and balanced evaluation was carried out. The approach was taken as the auditors' thoroughness was found to be varied in the earlier two audits. A greater emphasis was also given to departments or divisions with high non-compliances from the previous audits, especially those, which had non-compliances that were not rectified.

From the third internal audit, it was found that the laboratory staffs were still grappling with the understanding and implementation of the documented procedures despite having undergone several training workshops conducted by the Area Coordinators. A hands-on training approach was then taken to ensure a thorough understanding. As far as the support administrative staffs were concerned only a minimal fine-tuning was required as their work 
had all the while been involved with paperwork. Nearly all faculties were giving their support to ensure compliance.

The School saw a sudden increase in ISO 9001 related activities ever since the launching of the trial implementation phase. On average six ISO related activities were held per month in the year 2000 at the School of Engineering ${ }^{[7]}$. The bustling activities also helped to remind staffs that the School was serious for certification. The financial resources allocated had enabled these activities to be conducted with ease. In fact any ISO 9001 related activities were given the 'green lane' by the School.

Finally came the Compliance Audit in August 2001, nearly 10 months after the Adequacy Audit, and the School passed it without any non-compliances. The whole exercise which started in May 1999 and ended in August 2001 (27 months) exceeded the targeted 24 months. The three month extension was partly attributed to the shifting into the new engineering complex. All the hard work put into establishing the quality system and ensuring its efficient implementation was felt rewarded. It was concluded that a thorough understanding by the staff and persistence monitoring were required to attain certification and maintain the 'newly' installed system.

\section{Quality Assurance Structure}

Prior to certification there were a steering committee and a core group for developing procedures. The steering committee later evolved into Quality Assurance (QA) Committee and Action Committee. The five-person members of the QA Committee were responsible for coordinating the ISO 9001 related activities whereas the Action Committee comprising the Area Coordinators and the deputies together with the QA Committee members were responsible to implement the decisions of the School and QA Committee and monitor the performance of the respective departments and divisions. Some departments went further to form their own QA departmental committee to reduce the workload of the Area Coordinators.

Upon certification, a QA Unit was formally formed, and the appointed head was included in the School's management. The Head of Unit was also appointed as the Management Representative for the quality system. The QA Committee was renamed QA Council and expanded to 10 members while the Action Committee was maintained. With a formal QA Unit and the support from the QA Council it was expected that the management of the quality system would be more efficient. The Unit was responsible for the administrative aspects and answerable to the Dean of the School whereas the QA Council remained as the guardian of the quality system.

The QA Council comprises a Management Representative, Deputy Management Representative, Internal Audit Coordinator, Coordinator of Area Coordinators and six other members. Each of the QA Council members is also given a specific portfolio, such as training, research and consultancy. The QA Council members and the Area Coordinators are also given a reduction of $50 \%$ in the teaching load. The QA Council is also being referred to by the University to assist other schools in establishing their quality system. Currently, a team from the QA Council is involved in helping the School of Science \& Environmental Studies by providing training and assisting them in their internal audit. The Institution of Engineers Malaysia has also recently appointed a team from the QA Council to review their quality system and convert it into the ISO 9001-2000 version. 


\section{Improved Performance with the ISO 9001 Implementation}

The School as a whole saw improvement in the performance of the academic staff based upon the student assessment. Table 1 shows the performance of the academic staff at the Department of Civil Engineering during the implementation stage. There is a significant increase in the number of academic staff scoring above 4.00 out of 5.00 in the November 2000/01 semester (a total of $75 \%$ of the staff as compared to less than $30 \%$ a year before). The evaluation at the School level also indicates an increasing trend of academic staff attaining high scores, as shown in Table 2. Students thus benefit from the implementation of the quality system in teaching. As a whole there are numerous benefit to the client (students), such as, outright cancellation of classes is not allowed, classes must be run during the day, punctuality of academic staff is emphasized, teaching plan must be provided and adhered to, examination questions and marks are moderated. The quality system is more transparent in that students can provide their feedbacks without fear of reprisals. Complaints on teaching or related to teaching environment are being dealt swiftly as they are monitored closely.

Students are seeing their rights and beginning to act responsibly. Recording of the class attendance emphasizes the importance of attending classes. Poor performing students are required to see their respective lecturers for counseling and discussion. Parents of students who are getting poor grades are being informed of their children performance.

Immediate improvement is visible in students performance in terms of the number of achievers in the Dean's List and the reduction of 'drop-outs' as shown in Table 3 and 4 respectively.

Table 1: Results of Faculty Teaching Evaluation at the Department of Civil Engineering, Universiti Putra Malaysia

\begin{tabular}{|c|c|c|c|}
\hline Category & Nov 99 (\%) & May 00 $(\%)$ & Nov 00 (\%) \\
\hline$<3.00$ & $0(0 \%)$ & $0(0 \%)$ & $0(0 \%)$ \\
\hline $3.00-3.99$ & $16(76.2 \%)$ & $21(56.8 \%)$ & $8(25.0 \%)$ \\
\hline$>4.00$ & $5(23.8 \%)$ & $16(43.2 \%)$ & $24(75.0 \%)$ \\
\hline Total & 21 & 37 & 32 \\
\hline
\end{tabular}

Table 2: Results of Faculty Teaching Evaluation at the School of Engineering, Universiti Putra Malaysia

\begin{tabular}{|c|c|c|c|c|c|c|}
\hline Category & May 98 & Nov 98 & May 99 & Nov 99 & May 00 & Nov 00 \\
\hline$<3.00$ & $9(11.4 \%)$ & $1(1.1 \%)$ & $3(3.1 \%)$ & $2(1.9 \%)$ & $3(1.8 \%)$ & $1(0.6 \%)$ \\
\hline $3.00-3.99$ & $60(75.9 \%)$ & $60(66.7 \%)$ & $61(62.2 \%)$ & $73(72.3 \%)$ & $90(54.9 \%)$ & $76(45.5 \%)$ \\
\hline$>4.00$ & $10(12.7 \%)$ & $29(32.2 \%)$ & $34(34.7 \%)$ & $26(25.8 \%)$ & $71(43.3 \%)$ & $90(53.9 \%)$ \\
\hline Total & 79 & 90 & 98 & 101 & 164 & 167 \\
\hline
\end{tabular}


Table 3: Results of Dean's List

\begin{tabular}{|c|c|}
\hline & Total Number of Students \\
\hline Before ISO Implementation & 762 \\
\hline After ISO Implementation & 936 \\
\hline
\end{tabular}

Table 4: Status of Drop-Outs

\begin{tabular}{|c|c|c|c|}
\hline CATEGORY & May 00 & Nov 00 & May 01 \\
\hline Total Number of Students & 2372 & 2547 & 2506 \\
\hline Number of Drop-Outs & 74 & 48 & 46 \\
Percentage & $3 \%$ & $2 \%$ & $2 \%$ \\
\hline
\end{tabular}

\section{Conclusion}

Establishing a quality system requires a huge effort by all. In the case of the School of Engineering at the Universiti Putra Malaysia the sheer determination of the management to put the system in place had contributed tremendously to the successful certification and implementation. The Council, comprising those who started building the quality system, is the guardian of the system ensuring that the spirit of the established system is continued. Training and especially the hands-on versions are instrumental is getting the staff to participate in upholding the system as they are more aware of the requirements. Improvement in the academic staff performance is among the fruits of success when implementing the quality system. This client-focused approach also produces a more responsible student, after seeing the efforts by the School to provide them with motivated lecturers and better learning environment. Increasing trend in the number of students achieving the Dean List and the reduction of 'drop-outs' showed that students directly benefited from the quality system.

Despite the long hours spent in documenting the procedures and monitoring the implementation, the certified status without non-compliance during the Compliance Audit provides the impetus to sustain the system further. The teamwork that had developed during the building up of the system and its implementation is indeed invaluable, and it has led to greater involvement and interaction among these academic staffs in the field of research and services.

\section{References}

1. Ketola, J. and Roberts, K .2001. ISO9000:2000 In a Nutshell, Paton Press.

2. Goetsch, D.L and Davis, S.B .1998. Understanding and Implementing ISO 9000 and ISO standards, Prentice Hall

3. Thomas, K. 1996. How To Keep ISO 9000, Kogan Page Limited.

4. Schlickman, J.J. 1998. Quality Management System Design, Lancaster Press Inc.

5. Rao, S.S., Ragunathan ,T.S and Solis, L.E. 1997. Does ISO 9000 have an effect on quality? An international empirical study. Total Quality Management. 8 (6): 335 -346 
6. Calingo, L.M.R., Leong, Y.M., Chia, M.P. and Mohamed, H. 1995. Achieving total quality management through ISO 9000: a research note. Accounting and Business Review. 2(1): 173 -186

7. Anon. 2000. Laporan Tahunan 2000 Fakulti Kejuruteraan. Universiti Putra Malaysia

\section{Biography}

MEGAT JOHARI MEGAT MOHD NOOR is an Associate Professor at the Department of Civil Engineering at Universiti Putra Malaysia and also a registered Professional Engineer. He obtained his BSc(Hons) in Civil Engineering and MSc in Water and Waste Engineering at Loughborough University in 1982 and 1984 respectively. He is an Executive Director of the Feder ation of Engineering Institutions of Islamic Countries.

MOHD RASID OSMAN is a Senior Lecturer at the Department of Mechanical \& Manufacturing Engineering at the Universiti Putra Malaysia. He obtained his BSc(Hons) in Mechanical Engineering and MSc in Engi neering Production from the United Kingdom. He is presently heading the Quality Assurance Unit at the School of Engineering at Universiti Putra Malaysia.

NOR KAMARIAH NOORDIN is the Head of the Department of Computer and Communication Engineering at the Universiti Putra Malaysia. She obtained her BSc in Electrical Engineering (Telecommunications) at University of Alabama, and her Masters in Malaysia. She is also the Coordinator of the School of Engineering Internal Audit.

RAHMAN WAGIRAN is a Senior Lec turer at the Department of Electrical and Electronic Engineering at the Universiti Putra Malaysia. He is also the document control officer for the quality system implemented at the School of Engineering.

DESA AHMAD is an Associate Professor and Deputy Dea $\mathrm{n}$ at the School of Engineering, Universiti Putra Malaysia. He is in charged of the academic affairs at the School. He was also the first Management Representative for the School and now appointed an advisor of the quality system.

MOHD SALEH JAAFAR is the Head of the Department of Civil Engineering at Universiti Putra Malaysia. He holds a PhD degree from Sheffield University, United Kingdom. He also coordinates ISO 9001 related training programmes for the School.

ZAINUDDIN MOHD YUSOF is a lecturer at the D epartment of Civil Engineering, Universiti Putra Malaysia. $\mathrm{He}$ is the Area Coordinator for the Department of Civil Engineering who coordinates ISO 9001 related activities.

RADIN UMAR RADIN SOHADI is a Professor and Dean at the School of Engineering, Unive rsiti Putra Malaysia. He graduated from Sheffield University and Birmingham University in the United Kingdom. He had been instrumental in keeping the ISO 9001 certification for the School to remain on track. 